Bangladesh Journal of Anatomy January 2009, Vol. 7 No. 1 pp. 45-48

\title{
Effects of Insulin treated Established Diabetes Mellitus (EDM) on the Volume of Placental Parenchyma and Weight of the Neonate
}

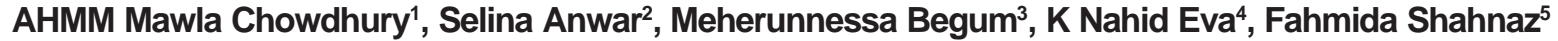

\begin{abstract}
Taking in mind the effects of diabetes mellitus of varying severity on human placenta and their implication on the well being of the fetus, a quantitative study at the macroscopic level was designed. Sixty post caesarean section human placentas were studied of which thirty were from mothers having insulin treated established diabetes mellitus (EDM) considered as EDM group and thirty were from control mother having no diabetes mellitus. The venous plasma glucose level (fasting and two hours after breakfast) of the diabetic mothers in second and third trimester were recorded and the mean of the values were calculated. The value ranged from 5.93 to 10.10 and the mean was $7.28 \pm 0.90$. The two groups did not differ significantly from each other with age, weight, height, or parity of the mother or in gestational age. Parenchymal volume in control and EDM group were $300.14 \pm 75.43$ and $309.25 \pm 61.64$ respectively.
\end{abstract}

The value showed higher mean value in EDM group. The differences did not reach a significant level. The neonatal weight in control and EDM group were $2.95 \pm 0.53$ and $3.05 \pm 0.52$ respectively. The neonate did show a tendency towards being heavier in EDM group, but no reached the significant level. There was a significant positive correlation between the neonatal weight and the parenchymal volume in control and EDM groups.

Key words: Established Diabetes Mellitus, Placenta, Parenchyma, Neonates.

Introduction:

The placenta involves in the transfer of maternal nutrients, oxygen and heat to the fetus and in reverse transfer of metabolic waste products to the maternal circulation. The placental tissue can be expressed as a sum of parenchymal, non-parenchymal and pathological components ${ }^{1}$. The parenchyma consists of villi with their vessels and maternal intervillous space, the non-parenchyma consists of chorionic and decidual plates, fetal vessels of diameter greater than $0.1 \mathrm{~mm}$ and maternal inter cotyledonary septa. The most common pathological

1. Associate Professor, Department of Anatomy, Sir Salimullah Medical College, Dhaka.

2. Associate Professor (CC), Department of Anatomy, Rangpur Medical College, Rangpur.

3. Associate Professor, Department of Anatomy, Sir Salimullah Medical College, Dhaka.

4. Medical Officer, MCH\&FP, Chirirbandor Health Complex, Dinajpur.

5. Medical Officer, MCH\&FP (IMO), Department of Gynae \& Obs, Dhaka Medical College, Dhaka.

Correspondence: Dr. AHMM Mawla Chowdhury components are old and recent infarcts and subchorionic fibrin.

The architecture of the placenta has been claimed to be changed in maternal diseases like diabetes mellitus ${ }^{2,3,4,5}$. Antepartum maternal hyperglycemia in diabetic pregnancy is associated with impaired uterine blood flow ${ }^{6}$. Uteroplacenta ischaemia could be responsible for most of the observed placental changes $^{7}$. The degree of metabolic control of the maternal diabetes are important variables to be considered when studying the placenta ${ }^{8}$.

Considering the placental structure and the clinical condition like Established Diabetes Mellitus (EDM), the present study was aimed at the macroscopic determination of volume of placental parenchyma and weight of the neonate and at the same time it was assumed that the study would open a new avenue of thinking the feto-placental relationship.

\section{Materials and Methods:}

Thirty placentas were collected from the mothers who were the patients registered by the Diabetic 
Association of Bangladesh as having established diabetes mellitus (EDM) before the onset of current pregnancy. All the diabetic mothers were treated with insulin during the period of gestation. The venous plasma glucose level (fasting and two hours after breakfast) of the diabetic mothers in second and third trimester were recorded and the mean of the values were calculated. The value ranged from 5.93 to 10.10 and the mean was $7.28 \pm 0.90$. A control group of placentas was obtained from thirty healthy women who were similar to the study group of diabetic women with respect to age, weight, height and parity. Undergoing caesarian section, all mothers gave birth to a living baby after completion of a gestational period between 37 weeks and 40 weeks in the Department of Obstetrics and Gynecology of BIRDEM Hospital, Dhaka between June 2000 and January 2001. The mother who had a previous history of hypertension, pre-celompsia or had and Rh negative blood group or was positive for VDRL \& HBsAg were excluded from the study.

The placentae were collected just after delivery. The umbilical cord was cut off at $2.5 \mathrm{~cm}$ from its insertion. The placenta was examined carefully. After removing blood and trimming the membranes the placenta was mopped with cotton wool. Each placenta was looked for any abnormality like necrosis, infarction, Cysts etc and if found it was recorded. Then the total volume of the placenta was determined by displacement of water in a backet and then measured in a graduated cylinder marked in milliliter $(\mathrm{ml})$. The placenta was them fixed in $10 \%$ formalin.

The formalin fixed placenta was then sliced cutting from maternal to fetal surface, each slice having a breath of $1 \mathrm{~cm}$. Each slice thus has a fetal surface, and maternal and internal surface. The internal surface was carefully examined for any unusual thickness or change of colour.

The volume of the parenchymal, non-parenchymal and pathological components were determined by the point counting technique for gross specimen ${ }^{9}$ (Fig-1). The principle depends on the fact that in a composite organ, the volumes of the components are equivalent numerically to the relative areas occupied by these components on cut surfaces. If a grid of regularly spaced points are placed over the cut surface, the number of points over these components will be proportional to their area and hence, to their volumes.

In the present study, a computer-generated grid composed of points spaced $0.5 \mathrm{~cm}$ apart printed on a plastic sheet, was placed on the internal surface of a slice of the parenchyma, nonparenchyma or any pathological component of the slice was recorded on a specially formed sheet.

Thus the placenta was studied beginning from the slice of one end proceeding to the other. A highest number of 1000 points were recorded in this way. Thus the percentage to the points falling on the parenchyma and non-parenchyma was calculated. These percentages thus represented the proportional volumes of these components. As the total volume of the placenta had already been determined by the method of displacement of water. The absolute volume of parenchyma and nonparenchyma could simple be calculated.

Before slicing the placentas for estimation of volumes of parenchyma and non-parenchyma each placenta was given a code number by one of the fellow researchers, making the present researchers blend about the groups of placenta. After taking the data the placentas were decoded.

\section{Results:}

In the present study, the findings of the two groups were compared with each other. The table-I displays the total volume in Control and EDM groups. The mean volume of the placenta was larger in the EDM group than in the control group. The table also displays parenchymal and no parenchymal volume. The mean parenchymal volume is higher in the EDM group than in the control group and the mean non parenchymal volume was lower in EDM group than the control group. However the groups did not vary significantly from each other in this regard.

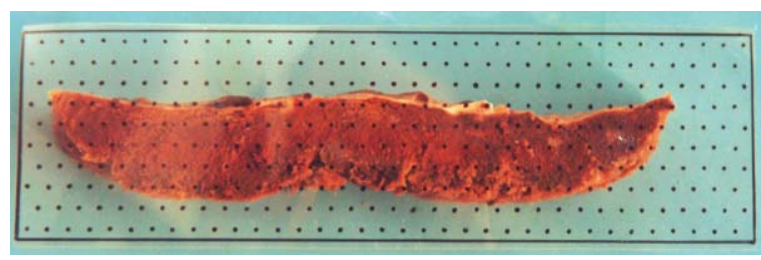

Fig.-1: Photograph of the slice of a placenta showing the procedure of point counting using the computer generated plastic grid placed on the cut surface of the slice. 
Table-II shows the weight of the neonate in different groups. The mean birth weight of EDM group were larger than of the control group. The difference was not statistically significant. Fig.-2 shows association between neonatal weight $\&$ absolute volume of the Parenchyma and Placenta.

\section{Table-I}

Showing the total, parenchymal and non-parcnchymal volume of placentas in different groups

\begin{tabular}{|c|c|c|}
\hline Variable & $\begin{array}{l}\text { Control } \\
(n=30)\end{array}$ & $\begin{array}{c}\text { Established } \\
\text { Diabetes Mellitus } \\
(\text { EDM })(n=30) \\
\end{array}$ \\
\hline \multicolumn{3}{|c|}{ Placental volume (ml) } \\
\hline \multicolumn{3}{|l|}{ Total } \\
\hline Range & $196-670$ & $211-505$ \\
\hline$($ Mean \pm SD) & $(380.13 \pm 98.17)$ & $(387.57 \pm 74.25)$ \\
\hline \multicolumn{3}{|l|}{ Parenchymal (ml) } \\
\hline $\begin{array}{l}\text { Range } \\
(\text { Mean } \pm S D)\end{array}$ & $\begin{array}{c}146.61-525.95 \\
(300.44 \pm 75.43)\end{array}$ & $\begin{array}{c}163.54-401.79 \\
(309.25 \pm 61.64)\end{array}$ \\
\hline \multicolumn{3}{|c|}{ Non-parenchymal (ml) } \\
\hline Range & 34.74- 144.72 & 30.21- 154.35 \\
\hline$($ Mean $\pm S D)$ & $(79.62 \pm 28.91)$ & $(77.93 \pm 24.45)$ \\
\hline
\end{tabular}

Statistical Significance level was set at 5\% (P 0.05).

An unpaired t test was used to compare between the control and EDM group.

No significant difference was found for any of the variables.

Table-II

Showing the weight of the neonate in different groups

\begin{tabular}{lcc}
\hline Variable & $\begin{array}{c}\text { Control } \\
(\mathrm{n}=30)\end{array}$ & $\begin{array}{c}\text { Established Diabetes } \\
\text { Mellitus (EDM) }(\mathrm{n}=30)\end{array}$ \\
\hline Birth weight $(\mathrm{Kg})$ & & \\
$\quad$ Range & $1.50-4.10$ & $2.00-4.00$ \\
$\quad$ Mean \pm SD) & $(2.95 \pm 0.53)$ & $(3.05 \pm 0.52)$ \\
\hline
\end{tabular}

The statistical significance level was set at 5\% ( $P £$ 0.05)

An unpaired t test was used to compare between the control EDM group.

No significant different was found for any of the variables.

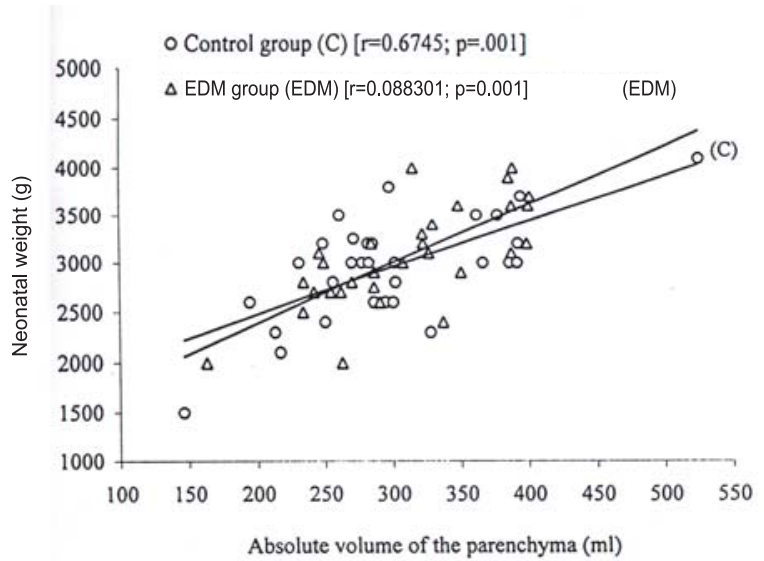

Fig.-2: Scatter diagram with regression analysis showing any association between neonatal weight and absolute volume of the parenchyma of the placenta in Control and EDM group ( $n=30$ in each group). The positive correlation was statistically significant in the two groups.

\section{Discussion}

Placental features like volume of the normal term placenta have chances of varying with maternal factors like age, weight, height and parity and gestational age. For this reason, the subjects of the present study were chosen in such a way that the two groups did not show any significant difference between them regarding these factors.

Anwar ${ }^{10}$ observed significantly increased amount of parenchymal tissue in the established (overt) as well as in the gestational diabetes. Melthus, Barua ${ }^{11}$ also observed a tendency towards an increase in the absolute volume of the parenchyma in gestational diabetes although this difference did not reach a level of statistically significant.

In the present study, neither the proportional nor absolute volume of the parenchyma or nonparenchyma in the EDM groups differed significantly from that in the control group. But if a trend is to be looked for it may be said that there was a tendency of a parenchymal increase in EDM group. ${ }^{9}$

Boeyd et al. ${ }^{12}$ worked on insulin dependent diabetes mellitus and found significant increase in both the absolute and relative. Volume of the parenchyma. May hew and Sisly ${ }^{13}$ found no significant difference in the volume of the parenchyma between the diabetic and control groups.

In the present study, the neonatal weight did not show any significant difference in the EDM group, 
but mean neonatal weight in the EDM group was higher in the EDM group than the control group.

A significant positives correlation was found between the absolute volume of parenchyma and neonatal weight in control and EDM group. Teasdale and Jean Jaques ${ }^{14}$ observed in placentas of white class $A$, $B, C$ that the qualitative morphological changes in the placentas of larger for gestational age infants were characterized by proportional increase in parenchymal tissue and cellular content and in the surface areas of exchange between mother and fetus in terms of peripheral villous and capillary surface areas and intervillous space volume. They observed highly significant increase in the total tropoblastic surface area, which was in favour of the theory that placental function was probably not adversely affected in the placentas of these diabetic and that such placentas efficiently support the growth of the large fetus.

Teasdale ${ }^{15,16}$ suggested that increased nutritional supply through the placental due to its structural enlargement in diabetic placenta may be the reason for higher birth weight in the babies of diabetic mother.

So from the present study it could be stated that as the parenchyma involved in fetomaternal exchange, the increase in parenchymal mass might be due to compensatory mechanism to support the growth and development of the large birth weight of the fetus.

\section{Acknowledgment}

We gratefully acknowledge Prof. Hosne Ara Tahmin, Prof. Shamim Ara and Prof. Humaira Naushaba for their moral support, guidance and encouragement to perform this research work.

\section{References:}

1. Laga EM, Discroll SG, Munro HN. Quantitative study of human placenta: Morphometry. Biol Neonatol 1973; 23: 231-59.

2. Mayhew TM. Patterns of villous and intervillous space growth in human placentas from normal and abnormal pregnancies. Eur J Obstet Gynecol Reprod Biol 1967; 68: 75-82.

3. Bjork O, Persson B. Plaental changes in relation to the degree of metabolic control in diabetes mellitus. Placenta 1982; 3: 367-78.

4. Honda M, Toyoda C, Nakabayashi M, Omori Y. Quantitative investigations of placental terminal villi in maternal diabetes mellitus by scanning and transmission election microscopy. Tohoku J Exp Med 1992; 167: 247-57.

5. Winick M, Noble A. Cellular growth in human placenta. II. Diabetes mellitus. J Paediatr 1967; 71: 216-9.

6. Widness JA, Teramo KA, Clemons GK, Voutilainen P, Stenman UH, Mckinlay SM, et al. Direct relationship of antepartum glucose control and fetal in erythropoietin pregnancy. Diabetologia 1990; 33: 378-83.

7. Eriksson UJ, Jansson L. Diabetes in pregnancy: decreased placental blood flow and disturbed fetal development in the rat. Paediatric research 1984; 18: 735-8.

8. Bjork $\mathrm{O}$, Persson B.Villous structure in different parts of the cotyledon in placentas of insulindependent diabetic women. Acta Obstet Gynecol Scand 1984; 63: 37-43.

9. Aherne W and Dunnil MS. Quantitative aspects of placental structure. J Pathol Bacterial 1966; 91: 123-6.

10. Anwar S. The gross and histological features of the human diabetic placenta a case control study [Thesis]. Dhaka: University of Dhaka, 1999.

11. Barua R. Macroscopic and Microscopic changes of human placenta in gestational diabetes and eclampsia [Thesis], Dhaka: BSMMU, 2002.

12. Boyd PA, Scott A, Keeling JW. Quantitative structural studies, on placentas from pregnancies complicated by diabetes mellitus. Br J Obstet Gynaecol 1986; 93: 31-5.

13. Mayhew TM, Sisly I. Quantitative studies on cilli, trophoblast and intervillous pores of placentae from women with well-controlled diabetes mellitus. Placenta 1998; 19: 371-7.

14. Teasdale F, Jaques GJ. Morphometry of the microvillus membrane of the human placenta in maternal diabetes mellitus. Placenta 1986; 7: 81-8.

15. Teasdale F. Histomorphometry of human placenta in class $B$ diabetes mellitus. Placenta 1983; 4: 1-2.

16. Teasdale F. Histomorphometry of human placenta in class $\mathrm{C}$ diabetes mellitus. Placenta 1985; 6: 69-82. 